Vachon, Geneviève, et al. "An Interdisciplinary and Intersectoral Actionresearch Method: Case-Study of Climate Change Adaptation by Cities Using Participatory Web 2.0 Urban Design." Enquiry 10.1 (2013) 14-28.

\section{An Interdisciplinary and Intersectoral Action-research Method: Case-Study of Climate Change Adaptation by Cities Using Participatory Web 2.0 Urban Design}

\author{
Geneviève Vachon \\ Marie-Noël Chouinard \\ Geneviève Cloutier \\ Catherine Dubois \\ Carole Després
}

\begin{abstract}
This paper discusses the last segment of a three-year interdisciplinary and intersectoral action research on climate change and urban transformation. The project had, as one of its core missions, the role of imagining urban and architectural adaptations for urban neighbourhoods that would contribute to minimizing the negative impacts of climate change on people's comfort, health and safety. The first part of the paper describes the collaborative design and augmented participation method used in the context of Québec City, Canada. These include the design process conducted to imagine adaptation scenarios, the visual strategies undertaken to make these understandable for the population, and the Web 2.0 crowdsourcing approach forwarded to measure feasibility and social acceptability of the design and visualization strategies. The second part discusses three positive outcomes of the process. First, collaborative design conducted with intersectoral groups of experts constitutes a promising avenue to identify adaptations and evaluate their relevance. Second, crowdsourcing is a powerful tool to inform the general public about climate change including both negative and potential aspects. As well, the crowdsource model allows access to particular knowledge which empowered users to make changes around their homes and neighbourhoods or advocating action from their local government. Crowdsourcing is also an efficient tool to help understand what people know about the potential impact of climate change and how it bears on their comfort, health and safety. Third and finally, the design proposals and the evaluation comments generated by working closely with various stakeholders, along with the public on-line consultation, allow for the induction of pragmatic recommendations that can be used as decision aids by elected officials and civil servants to better prepare their municipalities for climate change.
\end{abstract}

Keywords: adaptation, climate change, crowdsourcing, urban design, social acceptability, collaboration, Web 2.0, participatory planning, architecture, interdisciplinary

\section{Introduction}

Cities are becoming key actors in tackling climate change. They are said to have the potential to become models of efficiency in that field by engaging themselves in innovative practices responding to the climate crisis (Bulkeley, 2010). The overall goal of public policies was, until recently, to determine ways to mitigate or attenuate climate change by reducing greenhouse gas emission, with little effort being put in adapting environments to prepare for climate change (Klein, Schipper \& Dessai, 2005; Perthuis, 2010). There is now a general agreement that climate will continue to change even if we attain the established greenhouse gas reduction targets (IPCC, 2007), with an upsurge in interest for adaptation planning. Because adaptation policies are relatively less costly to finance than mitigation policies - monitoring of sensitive infrastructures and greening, for example - and because they have the potential to improve people's quality of life, governments, especially local or municipal, are willing to deploy strategies in that field (Adger \& Vincent, 2005; Williams, Joynt \& Hopkins, 2010). With this in mind, local governments face similar unanswered questions and challenges: which urban strategies to put forward in order to adapt to something you don't actually see, perceive or has yet to happen, which adaptations to favour, on the basis of which data, and how to prioritize with so many dimensions to consider simultaneously such as seasonal climate, vulnerability of residents, diversity of urban forms, limited public financing, to name a few (Tompkins et al., 2010). What is more urgent? To construct dikes in order to prevent future floods from damaging houses or provide natural systems for storm water control? Matters of ethics and values are raised but administrations lack planning strategies and practical tools on which to base their decisions and choice for action in order to reduce the negative impacts of climate change on their municipalities.

This paper discusses these questions using the last segment of a three-year interdisciplinary and intersectoral action research project on climate change and urban transformation in Québec City, Canada ${ }^{1}$.

1. Undertaken in 2010, the project is entitled "Changements climatiques et transformation urbaine: un projet de recherche-action pour renforcer la resilience de la Communauté Métropolitaine de Québec". It is financed and realized in partnership with Ouranos, a consortium on climate change (www. ouranos.ca), as well as Québec governement's Fonds vert (www.mddefp.gouv. qc.ca/ministere/fonds-vert/) and Natural Resources Canada. 
The aim was to foster collective learning and decision-making regarding such an evolving problem (Boholm \& Löfstedt, 2004; Brown, Harris \& Russel, 2010), and help local administrations in their quest for adapting their territory to climate change (Hallegatte, 2009). One of its core missions was to imagine urban and architectural adaptations for urban neighbourhoods that would contribute to minimizing the negative impacts of climate change on people's comfort, health and safety. The research strategy is built on the concerted contribution of stakeholders from both public and private spheres living or working in the Québec metro area whose complementary expertise, knowledge and representations were likely to provide an accurate understanding of local urban challenges.

\subsection{Québec City in context}

Founded in 1608, Québec City is the capital of Québec, the Frenchspeaking province of Canada. Population forecasts mark it as one of the fastest aging cities in Canada; fertility and immigration rates will not be sufficient to ensure the replacement of older generations. The demographic forecasts indicate a population increase of about $1.1 \%$ by 2031 (down from $3.4 \%$ in 2011) (ISQ 2009). In spite of new households forming in the next ten years, a likely subsequent stagnation could make Québec a "shrinking city" after 2030.

Although most tourists only know of Québec City's picturesque historical centre, the sprawled nature of its metropolitan territory offers quite a different portrait with just over 750000 people spread on $3350 \mathrm{~km} 2$, for a low average density of 225 inhabitants per km2. This territory has expanded over four main periods: 1) the densification of the older «faubourgs» (1870 to 1910); 2) medium-density working class streetcar suburbs of triple-deckers distributed on an orthogonal street grid (1910 to 1940); 3) low-density post-war suburbs of bungalows and walk-ups clustered into mono-functional areas of impermeable street patterns (1950 to 1975); and 4) post-1980 exurbs of varied types and urban forms (Després, Vachon, Fortin, Gauthier \& Larochelle, forthcoming).

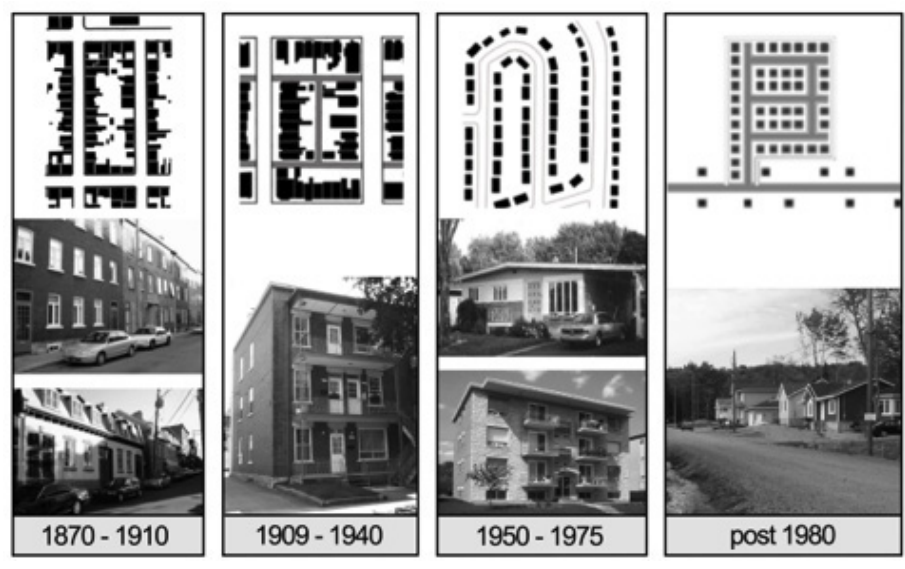

Figure 1: Main housing forms and types in suburban Québec (Després, Vachon et al, forthcoming)
Suburban developments are continuing to sprawl, with housing, commercial activities and jobs moving away from the city centre to the countryside. As owning a single-family detached house in a lowdensity development remains the dominant housing aspiration of most Québecers, including young families and retired people, developers are urging the expansion of the urbanization boundaries and the deregulation of protected agricultural land, forests and lakeshores. Consequently, the residential areas are dispersed within an over-developed yet aging road network with large homogeneous commercial areas and parking lots, as well as green spaces disconnected from neighbourhoods. All of these exacerbate the negative effects of urban heat islands, flash inundations or persistent smog on populations as extreme climatic episodes become more frequent.

Despite harsh winters that vary in duration and intensity, no major climate vulnerability is yet identified for the Québec metro area, with its relatively warm summers $\left(19^{\circ} \mathrm{C} / 66^{\circ} \mathrm{F}\right.$ on average in July according to Environment Canada). However, it is estimated that by the year 2050, the Québec City metropolitan area will undergo a variety of climate changes, primarily increases in mean precipitation, in mean temperatures and extreme climate-related events. In fact, temperatures in the southern parts of the province are expected to increase between $2.5^{\circ} \mathrm{C}\left(36.5^{\circ} \mathrm{F}\right)$ and $3.8^{\circ} \mathrm{C}$ $\left(38.8^{\circ} \mathrm{F}\right)$, especially in winter. Also, the increase in precipitation will be more significant in the winter (from $8.6 \%$ to $18.1 \%$ ) than in the summer (from 3\% to 12.1\%) by 2050 (Desjarlais et al., 2010). This being said, the climatic region of the southern part of the Québec province could experience a decrease in snow cover which, if effective, would negatively affect the water supply. The region could also be subjected to temperature fluctuation less during the winter and more during the summer. A major consequence would be an increase in the number of very hot days in the summertime ${ }^{2}$. The region is also expected to experience a greater number of heat waves, but also more snowstorms and heavy rainfall. In this regard, the frequency, intensity and duration of extreme climaterelated events should increase.

As a fairly typical North American urban context with regard to land use and planning, demographic outlook, and expected exposure to the risks of climate change, the Québec metro area represents an interesting case study for imagining fairly replicable architectural and urban adaptation scenarios, and testing their feasibility and social acceptability, the focus of this research.

\footnotetext{
2. For example, daytime temperatures reached 30 to $35^{\circ} \mathrm{C}$ for 7 consecutive days in southern Quebec from July 13 th to July 19 th 2013 , and did not drop below $20^{\circ} \mathrm{C}$ during the nights. The average daily maximum for the 7 days ranged between 29 and $32^{\circ} \mathrm{C}$, which is 4 to 5 degrees above the normal for this period of the year. Combined with the humidity (humidex factor), these temperatures felt like 35 to $45^{\circ} \mathrm{C}$ (Meteorological Service of Canada - Quebec Region, in partnership with Ouranos /www.climat-quebec.qc.ca; consulted December 2013).
} 


\subsection{The action-research project in context ${ }^{3}$}

The main objective of the action research was to study and find ways to increase urban resilience with regards to cities and their stakeholders' capacity to adapt to climate change. In co-developing knowledge on the effects of climate change on cities with designers and various stakeholders, the study contributes to the identification of possible and acceptable urban adaptations. The overall project started in 2010 and comprised three phases (fig.2). The first phase (year 1) aimed at identifying the specific aspects of the territory that are likely to be affected by climate change and mobilizing local stakeholders. This "diagnostic" phase involved a large number of stakeholders as urban experts (social service providers, water technical consultants, regional planners, interest groups, etc. $)^{4}$. The second phase (year 2) aimed at comparing urban areas in terms of their exposition to risks, such as accessibility to transportation and drinking water or urban heat islands, in order to map urban risks at the metropolitan scale. The third phase (year 3) aimed at designing and testing adaptation scenarios for strategic urban locations through an iterative process of collaborative design and augmented collaboration. This last phase of the project, conducted from August 2012 to September 2013, is the focus of this paper.

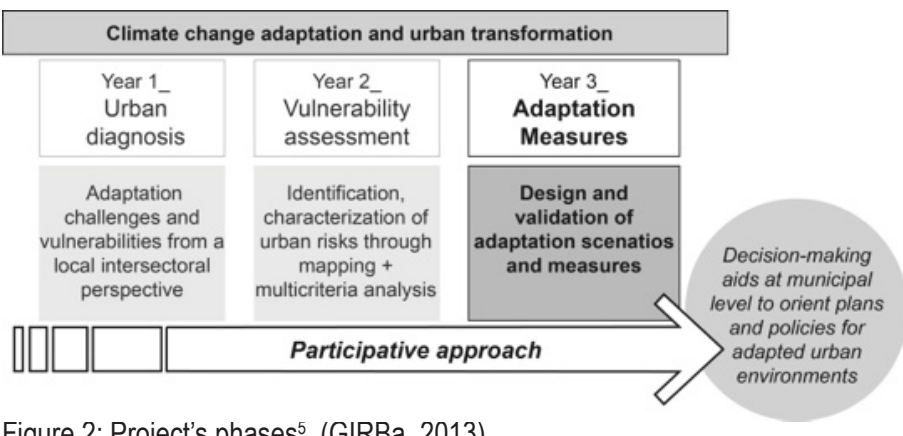

Figure 2: Project's phases ${ }^{5}$ (GIRBa, 2013)

3. The project is orchestrated by $F$ Joerin, head of the $G 2 C$ Institute at the Haute École d'Ingénierie et de Gestion du Canton de Vaud, Switzerland, with $\mathrm{G}$ Cloutier, post-doctoral candidate at Université Laval's Graduate School of Planning and Development (ESAD). Other members of the interdisciplinary research team from Université Laval comprise: C Després (architecture), A Potvin (architecture), M Rodriguez (planning), G Vachon (urban design), MH Vandersmissen (geography). The team also comprises doctoral candidates $\mathrm{C}$ Dubois (architecture) and C Legay (planning), research professional M Labarthe (geography), masters' candidate MN Chouinard (architecture), and many other graduate students.

4. For more on the diagnostic phase, see Chapters 1 and 2 of the final report, as well as Cloutier and Joerin (2012).

5. See also: www.ouranos.ca/media/publication/174_Joerin2011_WebEng.pdf (consulted August 2013).

\section{Augmented Participation: Web 2.0, Social Media and Crowdsourcing}

\subsection{Towards an ICT-supported strategy.}

This action research was conducted by the Interdisciplinary Research Group on Suburbs $\left(\mathrm{GIRBa}^{6}\right)$ based at the School of Architecture at Laval University, Québec City. The Group is composed of ten professors trained in anthropology, architecture, geomatics, planning, rural engineering and sociology. GIRBa annually welcomes research based graduate students $( \pm 15)$ and designers (30) through associated architectural and urban design advanced studios. GIRBa's work is characterized by a transdisciplinary research and action program aiming to identify solutions for retrofitting existing and ageing suburbs as a sustainable alternative to urban sprawl. It is formally organized around three types of research: empirical or scientific, architectural and urban design, and collaborative planning and design research. Over 15 years, GIRBa has orchestrated several action research and collaborative design processes involving a large number of stakeholders with various interests, expertise and knowledge. The objective is always to build consensus around a strategic and sustainable plan for consolidating different types and scales of suburban environments (Després, 2012; Després, Vachon et Fortin, 2011).

The Group is currently devising participatory processes relying on information and communication technology (ICT) as an innovative avenue to reach and engage stakeholders into complex discussions. This "augmented" process mostly relies on the interactive possibilities afforded by the Web 2.0, namely Internet surveys, crowdsourcing and social media ${ }^{7}$. Taking into account that $84,5 \%$ of households in the Québec metro area ${ }^{8}$ are connected to Internet in their homes (ISQ, 2012) and that the connection to Internet is becoming more common than fixed telephones lines, GIRBa hypothesizes that ICT-supported participatory processes can be used to effectively mobilize residents of a sprawled territory like Québec. These processes involve researchers, designers, decision-makers from the private and public sectors as well as elected officials and citizens. The conviction is that these stakeholders can not only inform sustainable development strategies, but also make them more sensitive to the needs, aspirations and cultural habits of the population.

GIRBa's proposed strategy is divided into five overlapping steps (fig. 3) aiming at: 1) mobilizing local actors by creating a momentum around the research problem in order to raise interest; 2) surveying

6. French acronym for Groupe Interdisciplinaire de Recherche sur les Banlieues. 7. The Web 2.0 is a concept introduced fairly recently to speak of a new Internet version centered on the participation and collaboration of users and their "collective intelligence" (O'Reilly, 2005).

8. In $2012,78 \%$ of adults in the province of Québec were regular Internet users. Even though this percentage is lower for older age groups, it still represents $56,2 \%$ of $55-64$ years old, and $23,9 \%$ of $65-74$ years old (CEFRIO, 2012). 
the population on issues relevant to the research problem with regards to everyday life, values and aspirations; 3) building scenarios through collaborative processes to envision what the future could look like to solve environmental challenges; 4) consulting experts and lay people to validate the sustainability, feasibility and social acceptability of the planning scenarios; and finally, 5) concerting around the most relevant scenarios, as adjusted from the results of consultation.

The augmented participation process developed for the project on urban adaptations to climate change presented in this paper was GIRBa's first attempt to test this strategy. The method will be replicated in Spring 2014 with specific considerations for the adaptation of the built environment to support independent aging, active living and social equity (Després \& Vachon, 2013). The following section discusses the advantages of augmented participation and presents recent experiments in different contexts.

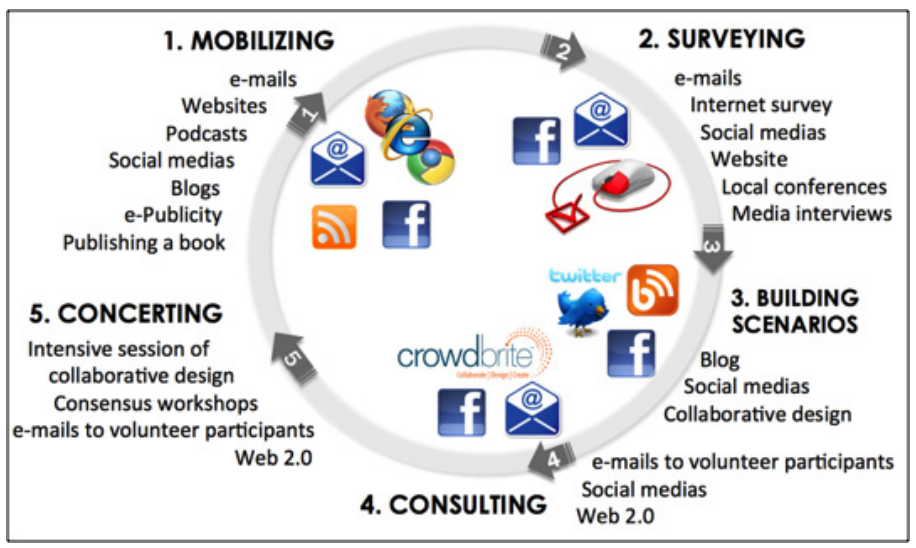

Figure 3: GIRBa's transdisciplinary and ICT-supported approach currently being developed (Després \& Vachon, 2013)

\subsection{Challenges of augmented participation}

Participatory processes in planning and urban design traditionally rely on a variety of activities to foster and engage discussion between participants (surveys, focus groups, design charrettes ${ }^{9}$ ) as well as complementary visualization tools and strategies (maps, plans, drawings, models) to inform and make proposals understandable for all participants. However, the popularity of digital technologies (smart phones, digital tablets) is booming. Combined with social media, these new technologies are influencing ways in which people access and share information but, more importantly, how they comment on societal issues. This has given birth to a communicational setting that has already modified the traditional quality of social engagement and interactions within a community, now defined more in terms of networks than physical proximity (Foth,

9. A charrette is an intensive participatory design activity, usually held during one or two days with groups of stakeholders.
2006). Researchers agree that digital technologies have the potential to complement, extend and renew participatory processes in planning and urban design (Brabham, 2012; Bugs et al., 2010; Dodge \& Kitchin, 2013; Gordon \& Manosevitch, 2010; Proulx, 2009; Steiniger et al, 2012; Stern et al., 2009). It is particularly true of Web 2.0 tools and applications that allow participants to take part in the process at anytime and from anywhere, relatively free of pressures (Stern et al., 2009). Digital and social media also allows for a better representation of local stakeholders (Al-Kodmany, 2000), as well as for local knowledge to emerge from both experts and lay people (Foth, 2006).

In the last ten years, considerable advances have been reported on the use of Web 2.0 tools to extend consultation processes in urban design and planning. Many experiments and ongoing research projects have proved their usefulness, especially in reaching more participants. Based on decentralization principles and simplicity of use, Web 2.0 is basically a network where information circulates rapidly for maximum interaction. It often implies user-generated content whereby users may contribute individually, as in blogs or social media, or collaboratively, as in wikis. Web 2.0 protocols are, in fact, acting as incubators for numerous popular or grass-root initiatives that use Internet, and social media to mobilize or activate citizens on a variety of issues. These range from the use of public spaces and the quality of services, to organization of manifestations, petitions or other forms of activism through creating online communities and forming new types of social interactions. Such social networks also contribute to feed what De Cindio \& Peraboni (2012) call a "collective conscience" towards important causes and have a tangible impact on information transmission and transparency in participatory processes. Climate Co-Lab is an online community using social media and whose goal is said to "harness the collective intelligence of thousands of people from all around the world to address global climate change"10. This Web site, developed by the MIT Center for Collective Intelligence, is described as an "on-line forum where citizens create, analyze and select detailed proposals for what to do about climate change" (citation). YouSayCity is another recently launched 3D online and interactive platform to "share and discuss ideas for [the] city, visualize 3D design proposals, and explore development projects in cities across the world"11.

Most of these initiatives, though, essentially support the communication of information and opinions; they are less about the emergence of new ideas (De Cindio \& Peraboni, 2012). This is why researchers claim that Web-based planning processes should not replace face-to-face interaction but rather act as a complement (Baek et al., 2011; Gordon et al., 2011; Gordon \& Manosevitch, 2010; Mandarano et al., 2010;

10. www.climatecolab.org (consulted on 27 August 2013).

11. As of August 2013, YouSayCity (www.yousaycity.com) is used by Ville de Montréal for a large online consultation regarding its urban development plan (Office de consultation publique de Montréal, www.ocpm.qc.ca, consulted on 27 August 2013). 
Slotterback, 2011; Stern et al., 2009). Indeed, having participants engage in dialogue and compromises on the Web is often more easily said than done (Baek et al., 2011, Steininger et al., 2012).

Crowdsourcing is a Web 2.0 participatory approach that is gaining popularity and accessibility for the purpose of planning processes. It consists of consulting a group of participants to spur online feedback on a proposal or set of ideas. This feedback is obtained in the form of comments or ideas, as well as from the adhesion to proposal through voting (Mandarano et al., 2010). Crowdsourcing is based on the notion that local expertise can emerge from the masses and become collective intelligence (Dodge \& Kitchin, 2013), thereby valuing "non-expert" or "non-mainstream" knowledge (Brabham, 2009). Crowdsourcing is thus useful to inform, mobilize, collect information at a distance, to contextualize issues, and to prompt adhesion through vetting proposed ideas. For instance, in a study using crowdsourcing to present the results of a bus stop design competition, Brabham (2009) explained that submitting a problem to a virtual community prompted and facilitated multiple perspectives and analyses, thus increasing the potential for groups to knowingly benefit from the problem-solving process. Compared to Geographical information systems (GIS) platforms, namely PPGIS ${ }^{12}$ prevalent in planning, crowdsourcing is considered a low-cost and accessible Web 2.0 technology (Steineger et al, 2012). In this regard, it is accessible to local governments looking to test proposals or policies during their elaboration with a maximum outreach to their population. Non-expert knowledge collected via a crowdsourcing consultation, by providing insights about places and local practices, can help define the perspective of future users in a most valuable way for both designers and decision-makers. Furthermore, such an interactive on-line consultation can potentially reach participants from different backgrounds that would not otherwise have attended a consultation meeting or participatory design session at a specified location or time.

For all the above reasons, a crowdsourcing platform was selected by GIRBa as a participatory Web 2.0 tool to work on the "wicked problem" of climate change (Rittel \& Webber, 1973 [1984]; Brown, Harris \& Russell, 2010). It appeared to be flexible enough to consult and concert with experts and non-experts about the feasibility and social acceptability of given urban adaptation scenarios, in combination with more standard participatory tools and activities.

\section{An Iterative and Augmented Process of Design and Consultation}

GIRBa's experience in participatory processes strongly confirms that design research is a legitimate and autonomous way of producing knowledge on a given problem, one that accepts intuition and uncertainty, that recognizes practical reasoning as well as material and organizational

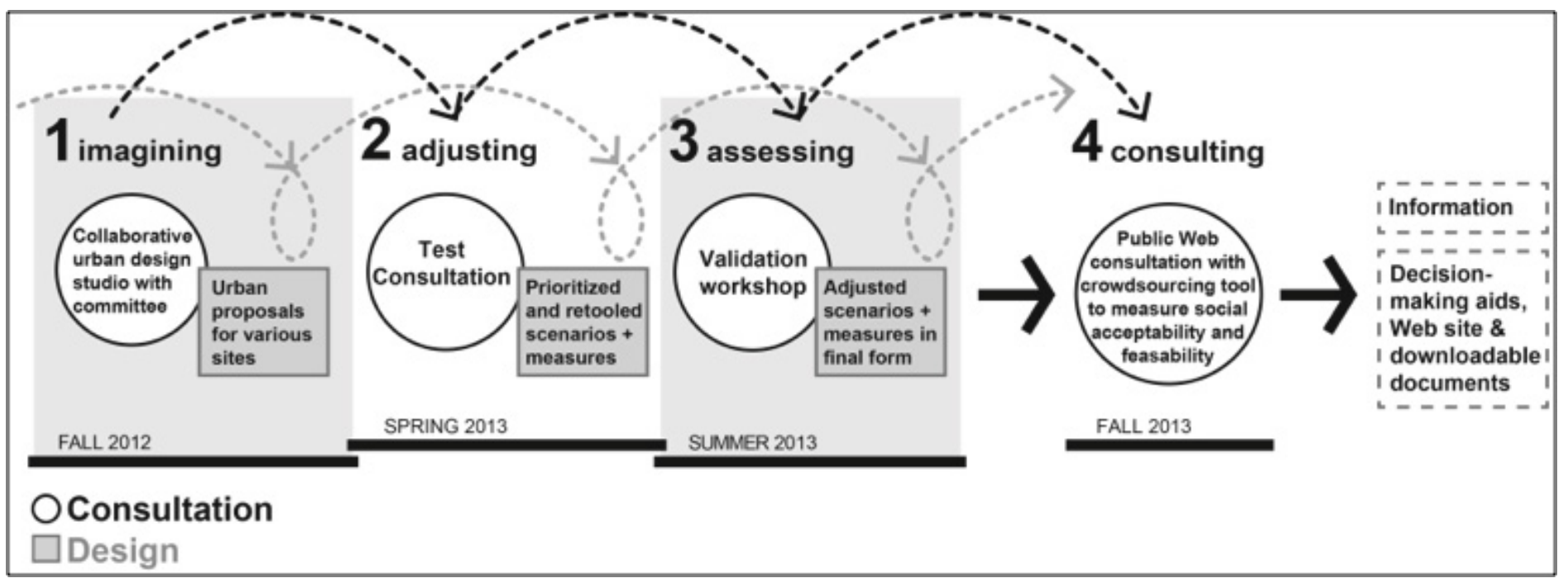

Figure 4:The collaborative design and consultation process (GIRBa, 2013)

12. Recent developments in PPGIS, or public participatory geographic information systems, are specifically oriented towards the mobilization and participation of populations, offering the possibility not only to comment on but also to bring geo-referenced modifications to a proposal in real time during an ongoing participatory process (Gordon \& Manosevitch, 2010). constraints, and that values public debate. The sequence with which knowledge is integrated and translated into the design process is both inductive and iterative, involving several loops during which proposals are constantly adjusted with additional information and evidence brought by users, decision-makers and experts (Després, Vachon \& Fortin, 2011). For these reasons, the method put forward in this action-research agenda bridges design and participation to develop socially acceptable 
evidence-based urban and architectural adaptation strategies. The collaborative strategy illustrated by Figure 4 was put forward based on several other premises. First, the complex and multidimensional nature of the challenges linked to climate change calls for a transdisciplinary and intersectoral process involving experts as well as lay people. Second, if the risks and consequences of climate change are relatively predictable, the ways in which to act upon such changes by adapting and transforming the built environment are less tangible. For this reason, it is important to be able to visualize in pragmatic ways how urban adaptations will impact the built environment. Third, the feasibility of eventual urban and architectural adaptations is quite unknown and needs to be assessed by experts. Finally, the acceptability of urban adaptations by the population is even less predictable, the potential impact of climate change being so abstract that citizens may feel either ambivalent or incompetent when faced with proposed solutions. The augmented process thereby combines traditional and Web 2.0 participatory design and evaluation methods to gradually produce local knowledge on viable and acceptable urban adaptations to climate change. Crowdsourcing is used in the process as a means for designers to evaluate in concert with groups sharing diverse interests and expertise. The final method comprises three main steps with the respective goals of: 1) imagining urban adaptation scenarios in collaboration with experts; 2) adjusting the visual representations of these scenarios and their accompanying textual information to make them understandable to experts and non-experts as well; and 3) assessing the scenarios' feasibility and social acceptability (fig. 4). Each step is detailed individually in the following sections, starting with a founding phase of gathering information and data during the first two years of the overall research project.

\subsection{Designing and Assessing the Adaptation Scenarios}

\section{Surveying local issues}

During the larger research agenda's first two years, a series of discussion workshops focused on assessing the perception and preoccupation of local stakeholders (representatives of community organizations, civil servants, business people) regarding ways in which Québec City's urban environments could be affected by climate change. The questions focused on what and where the main vulnerabilities existed, and what should the intervention priorities be. During Year 2, experts in domains related to transportation, drinking water management and built environments' exposure to heat were asked to link these perceptions and preoccupations to available data. The main preoccupations regarding these three climate change-related issues were: the microbiological quality and availability of drinking tap water during severe draughts, freeze-thaw cycles and heavy rainfalls (water management); the deterioration of infrastructures, such as roads and highways, by freeze-thaw cycles and by heavy precipitation (transportation); and the mitigation of urban heat island effects (built environments to heat).
Surprisingly, data to precisely assess the perceived risks and pinpoint priority actions was not always available or compatible. For example, no inventory or collated information pertaining to the surfacing materials used in the construction of streets and roads related to their location in the city was ever produced for Québec City. Also, since records of trees in the city's public domain are not kept, the urban tree canopy could not serve as a criterion for risk assessment of the urban heat island effect. This lack of information did not lead, as was originally intended, to the elaboration of detailed "priority risks" maps. Instead, the knowledge of local stakeholders (community members, organizations, social workers) and sectoral experts (transportation, water management, built environment) provided a common frame of reference to orientate the adaptation planning and design process. These "lessons learned" from local experiences, coupled with a survey of Québec's larger dynamics of change, formed a pool of reliable knowledge which informed the work conducted in the urban design studio with the mission to initiate transformation proposals.

The frame of reference also provided insight on shared vulnerabilities to climate change that needed to be taken into account in order to reinforce the suitability of adaptation measures. These social, economical and spatial vulnerabilities -- well documented in the literature (Adger, 2006; Birkmann, 2006) -- derived from an additional workshop aiming to explore the "neighbourhood effect" of climate change. Does a higher income "protect" a resident from being affected by severe storms or extreme heat? How does one's social network affect such vulnerabilities? The discussions eventually produced "figures" of vulnerabilities that would be useful further in the participatory process. However, this exploration of the neighbourhood effects of vulnerability in a climate change context remains preliminary and will have to be picked up in subsequent work.

\section{Imagining the scenarios}

This first step in realising the adaptation scenarios thus consisted of proposing actual urban and architectural transformations for different sectors of the Québec metro area. These sectors were selected on the basis of a map locating the most vulnerable areas for climate change, as identified by experts during Year 2 of the research project, in combination with the fact that they were either undergoing urban transformations or expected to in the near future ${ }^{13}$. The design proposals were developed over one semester by graduate students in the context of two urban design studios ${ }^{14}$, with the collaboration of interdisciplinary expert committees composed of elected officials, civil servants, planners, architects, developers from the private sector, representatives of NGOs

13. For more information about this phase of the project, see Cloutier and Joerin (2012).

14. In all, 8 teams of 4 students enrolled in the Master of Architecture and/or the Master of Urban Design programs at Laval University were involved during Fall 2012. Most projects can be viewed at www.atelierlabo-designurbain-ulaval.com. 
involved in sustainable planning, as well as researchers from the project team. During four one-day workshops spread through the semester, the experts discussed and evaluated the adaptation measures proposed by the students for new and existing residential areas. The interaction between experts and designers, but also among the experts themselves did not only lead to imaginative evidence-based adaptation scenarios for varied urban contexts, but also to a considerable amount of knowledge on the potential impacts of climate change at the local level (fig. 5).

The proposals' relevance to the urban and climatic contexts was examined through at least three feedback loops with the groups of experts: two one- of interpretation, adjustment and validation. In parallel to the workshops and charrette, members of the larger project's research team, along with other invited researchers (in planning and anthropology), informed the scenarios by providing technical support on climate-related issues. For example, trees have to be mature and form a large canopy in order to really contribute to the cooling of urban spaces. Urban agriculture is a simple and inviting way to add green productive areas to neighbourhoods while also providing efficient ways to manage runoff water and to mitigate heat island effects. However, land ownership issues and vandalism challenges need to be addressed to ensure such adaptations will also be

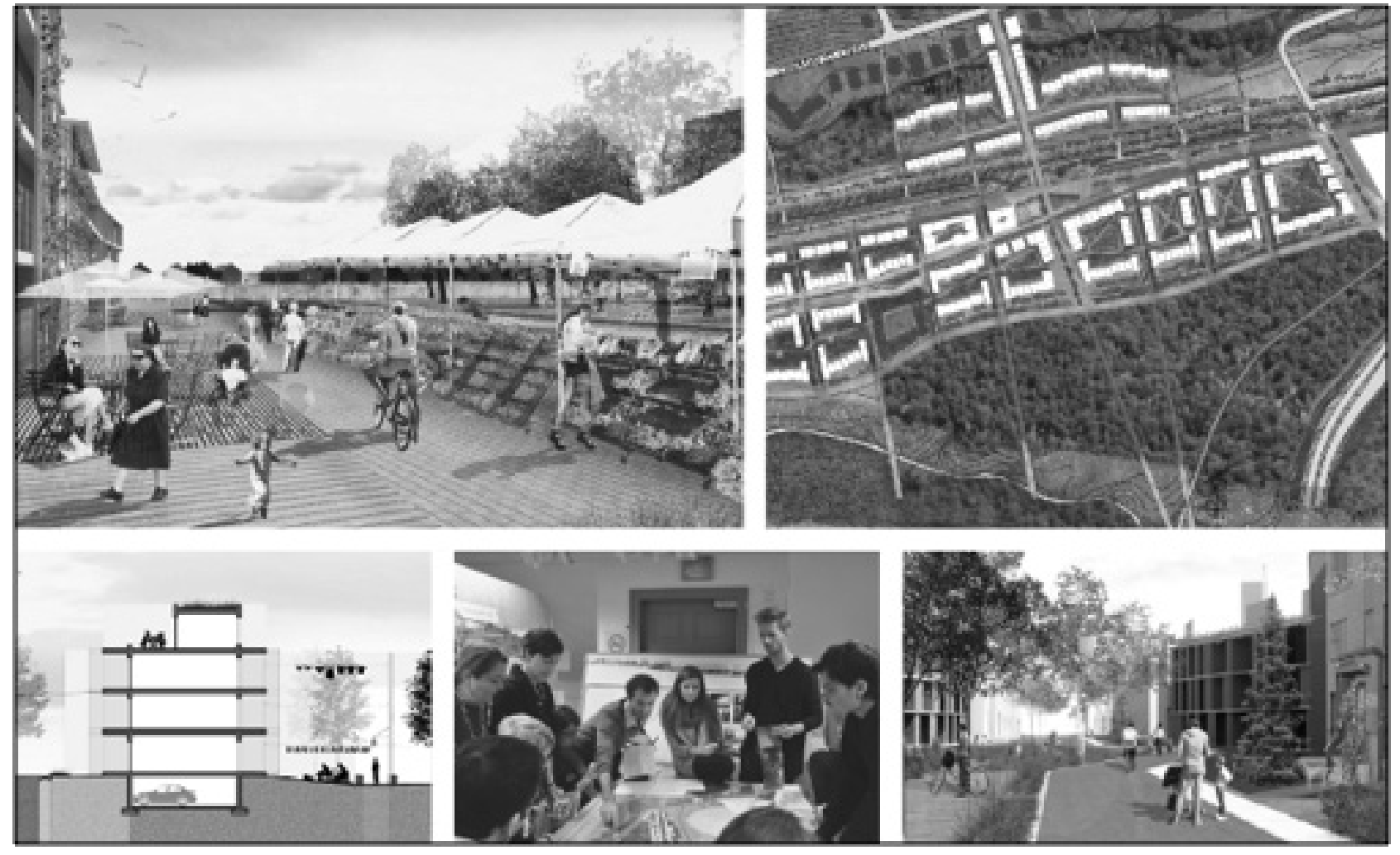

Figure 5: Urban proposals designed during a graduate urban design studio with an interdisciplinary committee of experts, Fall 2012 (GIRBa, 2013)

day workshops and one hands-on charrette. In every occasion, students, experts and members of the research team discussed and deliberated a large quantity of issues associated with the projects. For instance, they touched on residential densities which were objectively higher than those in neighbouring sectors but could be perceived positively by residents granted sufficient green spaces, interesting streetscapes, and good walkability. They also covered issues of more compact neighbourhood forms relying less on the use of cars, including less parking lots, and more on access to active modes of transportation. Again, the inductive and reflexive nature of the design process proceeded by iterative cycles a sustainable activity. Another example of water management concerned the salinity of the Saint Lawrence River, which is likely to increase upstream ${ }^{15}$ and could greatly affect the distribution of drinking water in the targeted sectors.

15. In the current context, fresh water in the Saint Lawrence first encounters oceanic salt water in the estuary near lle D'Orleans. A temperature increase of 2 to $4^{\circ} \mathrm{C}$ could lower the average flow of fresh water from Lake Ontario, the major source for the River, by nearly $25 \%$. Also, water levels in the downstream portion of the Saint Lawrence could rise from the upper estuary to the gulf, due to the melting of polar ice and thermal expansion of ocean masses. As a result, if climate warming continues unchecked, patterns would be modified, shore erosion accentuated and we can expect upwellings of salt water upstream (Environment Canada / www.ec.gc.ca; consulted Dec. 2013). 
By the end of the urban design studios, the next step consisted of sorting out the adaptation measures identified during the semester that offered the most potential and of producing scenarios that could be easily understood by experts and lay people as well. The criteria used to select these propositions were their relevancy to the urban and climatic context of Québec's metro area as well as their effective visual qualities to translate the principles. Indeed, the visual representations of the urban propositions to be eventually submitted for consultation needed to communicate or translate information as well as principles efficiently in order to collect valuable feedback, co-develop and evaluate ideas, and aid decision-making (Hayek, 2011). Preparing the visual material for the consultation implied choosing certain features over others for inclusion, and to allow for complex principles to be clearly demonstrated

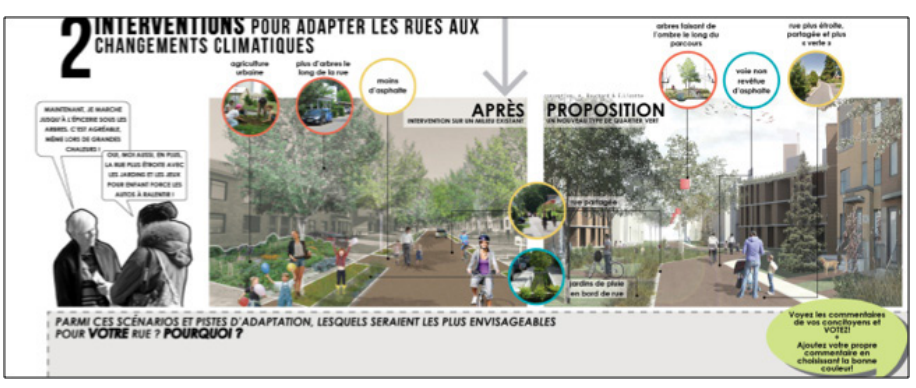

Figure 6: Transformation scenario for a typical street submitted to online pre-test consultation in April 2013 (GIRBa, 2013)

and communicated through representation. Participants need to be well informed on understandable scenarios in order to form and express their opinion with reference to their values and practices (Söderström, 2000). A diversity of representation modes helped attain this objective (Senbel \& Church, 2011). Abstract visual representations such as diagrams, plans and birds-eye views were useful to convey complex information about larger urban scales, whereas realistic images are useful to trigger a sense of concern about a given proposal, thereby prompting interiorised or implicit knowledge such as place-based or personal experiences and perceptions to emerge (Hayek, 2011).

\section{Adjusting the scenarios}

The next step consisted of assessing the extent to which the visual and textual content of the scenarios and adaptation measures could be understood by experts and non-experts. For this purpose, the visual material representing the adaptation scenarios and measures produced during the collaborative design studios were adjusted to ensure that they effectively supported discussion about their feasibility and social acceptability. Later on the visual material was pre-tested with citizens and experts exclusively using a crowdsourcing platform, for the citizens, and the combination of crowdsourcing and focus groups for the experts. The preparation of the visual material to be used for consultation was done with two goals in mind.
The first goal was to produce visual representations of potential climate change impacts such as effects of urban heat islands, and of supportive urban adaptations to counter their negative impacts such as adopting greening measures. This followed a process of selecting, prioritizing and interpreting the more relevant impacts and adaptation principles for transforming vulnerable neighbourhoods, streets and housing environments in the Québec metro area, conducted by members of the research team. With the help of "before and after" images, as well as a street-level view of the resulting urban ambiance, each visual scenario represented a set of impacts and adaptations in a different urban setting submitted to a set of extreme climate conditions such as sleet storms or heat waves (Fig. 6). Each adaptation strategy represented in a scenario referred to a fact sheet that explained, with text, photo or schema, its technical aspect and relevance. A second goal was to assure that the visual representations show a high degree of realism in terms of content and context. The images were constructed on the basis of typical and familiar urban settings found in Québec using normal framed views. The graphic language was chosen to ease comparisons and facilitate the evaluation of the scenarios with regard to their feasibility and social acceptability. Visual ambiguities were discussed among team members and remedied.

A total of three adaptation scenarios were eventually produced, each representing a different scale of intervention - the neighbourhood, the street and the dwelling. For example, an adapted street would include: sidewalks slightly sloped towards planting pits (acting as bioswales) to reduce flooding during rainstorms or heavy rainfalls; trees simultaneously tolerant to de-icing salt, resistant to drought and mature enough to provide shade; architectural shading devices; green or reflecting roofsurfacing materials; or resistant street furniture. Thirteen adaptation measures were illustrated and introduced in these scenarios. They were explained by way of fact sheets associated with each scenario. The scenarios were first pre-tested in the context of a graduate seminar research assignment ${ }^{16}$. An objective of this exercise was to have a first assessment of the feasibility and acceptability ${ }^{17}$ of the proposed adaptation measures in different urban contexts. Another objective was to compare the fertility of crowdsourcing with traditional focus groups for this task. Crowdbrite ${ }^{18}$ was selected as the crowdsourcing platform for the consultation. This non open-source tool was developed in San Francisco with the specific goal of catalyzing participation in planning, and is mainly used by planners, city officials, public and non-profit organizations, but also research groups.

For each the three scenarios, online and in-person participants were asked to write their opinion about the adaptation scenarios and their associated adaptation measures using Post-it notes that they could attach to specific features. The colour selected for the Post-it notes conveyed agreement (green), non-agreement (red), or neutrality or ambivalence (yellow) (fig.7). In the traditional workshops, small groups of experts met in face-to-face interaction for a half-day to discuss the 
scenarios. A different interactive strategy was tried in each group: the first one strictly used digital Post-it notes, the second one used strictly paper ones, and a third group used both. In the latter two, assigned secretaries transcribed comments on Crowdbrite digital Post-it notes, as the discussion went on. Since each group worked simultaneously in different rooms, all comments appeared online in real time and were visible to the three groups ${ }^{19}$. Each participant had a surname on Crowdbrite which offers multiple options to sort and filter comments, thus facilitating a quick validation during the participatory process.

This pre-test consultation yielded much information regarding the actual adaptation measures, their plausibility, feasibility and acceptability, as will be explored in a further section (Vachon, Cloutier, Chouinard et al, 2013). They oriented another round of re-design and adjustments, especially with regards to the scenarios' contextualization. The consulted groups found the scenarios representing built environments neither fully familiar nor completely recognizable, making if difficult to fully engage in their evaluation. They also felt overwhelmed by the large amount of proposed interventions. Therefore, the drawings had to be simplified in order to focus the attention on the adaptation measures. As for content, propositions had to be more realistic, especially with regards to Québec's low-density residential environments. Also, the look of certain adaptations to dwellings - such as brise-soleil - seemed "foreign" enough as to distract from the principle of providing shade with architectural amenities. Finally, the consulted groups found the scenarios to be disconnected from one another, as well as from the city as a whole. Such comments expressed during the pre-test oriented another round of re-design and adjustments, especially with regards to the scenarios' contextualization.

A total of eight scenarios were finally produced during a final iteration sequence: two at the neighbourhood scale (around a primary school sector and a church sector), three at the street level (a residential, a

16. The pre-test consultation was conducted by 20 students as part of their research assignment in the graduate Urban Forms and Cultural Practices seminar directed by C. Després in April 2013. Two activities were conducted in parallel: individual on-line interviews with citizens $(n=18)$, and a half-day workshop with experts $(n=18)$ divided into three focus groups.

17. Whereas feasibility refers to the technical, practical and economic aspects of the proposed adaptation measures, social acceptability refers to people's representation and perception of these adaptations' impact upon their community, according to different sets of values, backgrounds, etc.

18. Crowdbrite is self-described as "a fun and convenient way to participate in online brainstorming sessions, meetings, and workshops / charrettes". See http:// www.crowdbrite.com.

19. While the standard setting proved unsurprisingly conclusive in terms of the quality of interactions, the other settings were less successful in part because it took a while for new Crowdbrite users to learn how to use the platform in a short amount of time. It is agreed that participatory Web tools seem to limit the deliberative nature of interaction necessary to consensus building because participants tend to concentrate on the "how to" (Baek et al., 2011). commercial and a mixed-use street), and two at the scale of a housing lot (a single-family house and a multi-family building). In final, eighteen adaptation measures fact sheets were organized according to "levers for action" either on the urban form, on the architecture of buildings, on the natural cover, or on surface materials ${ }^{20}$. The measures were refined by the research team by taking into account Québec's climatic context, a cool temperate climate with high summer temperatures, and the practicality of their implementation. The eighteen measures were ultimately selected based on the fact that they were often examined and discussed throughout the action-research process and well documented in the literature. GIRBa's team also decided to design a fictitious city, "GirbaVille", an imaginary and abstracted map of a fairly typical municipality whose forms, densities, uses and architectural types remind those of Québec City without actually representing its actual territory (fig. 8). This allowed the ability to locate all eight adaptation scenarios on a single map and show how they simultaneously relate to a local environment and the larger urban territory. This points to the irreplaceability of the map during consultative processes whereby participants need to understand the

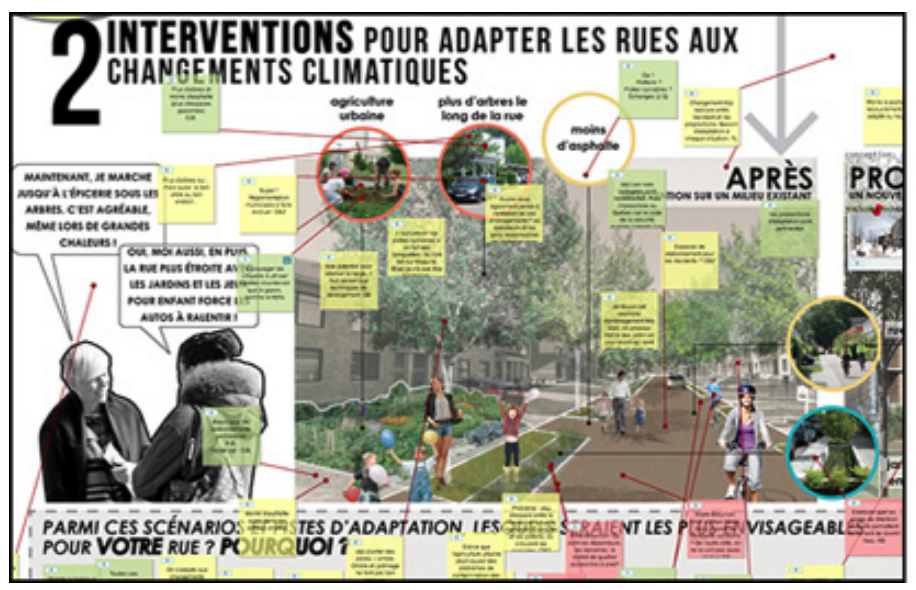

Figure 7: Example of a scenario assessed by non-experts using a crowdsourcing platform (GIRBa, 2013)

relationship between "pieces" of an urban environment by maintaining a link with the global (Söderström, 2000). The representations also had to be adjusted to facilitate online navigation on the Web-based consultation platform in order to support intuitive and non-linear modes of exploring the proposal's features, and "self-learn" about the underlying principles in one's own time. In this sense, the research team organised the scenarios as vertical Web-like pages. It also aimed for further visual simplification of the information, for instance by using logos to refer quickly to climate situations or fact sheets ${ }^{21}$. Figure 9 illustrates the finalized scenario for the school sector and Figure 10, an adaptation measure fact sheet.

\section{Assessing the scenarios}

This improved set of scenarios and adaptation measures underwent its final assessment round in Fall 2013. The evaluation of the measures by 


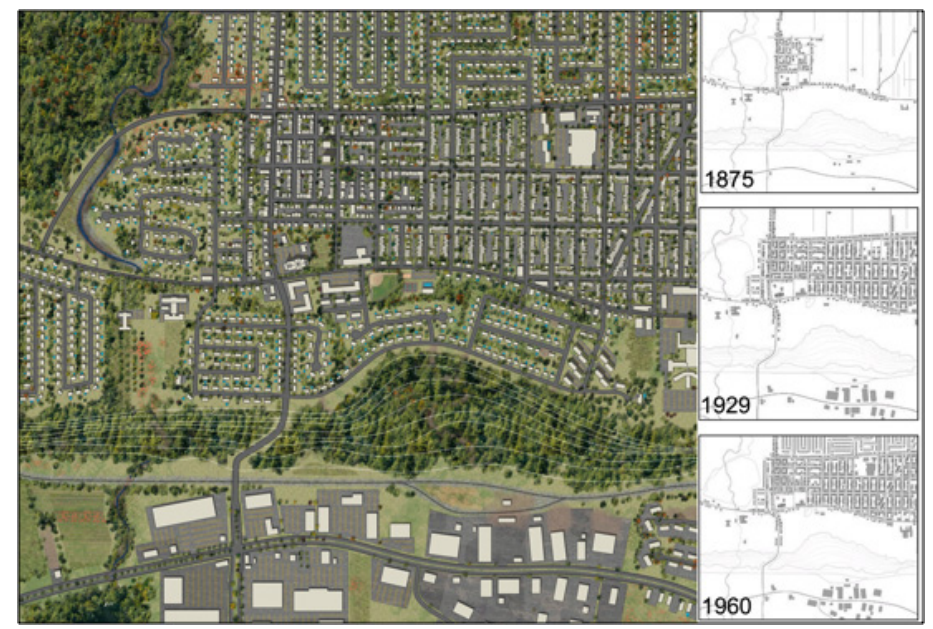

Figure 8: Part of GirbaVille with periods of morphological transformation (GIRBa, 2013)

experts was completed during a one-day in-person workshop in July and gathered twenty-two stakeholders, elected officials and experts on climate change, urban and community planning. The experts were divided into three focus groups. The research team first assessed their knowledge on climate change and its impact on cities with a paper and

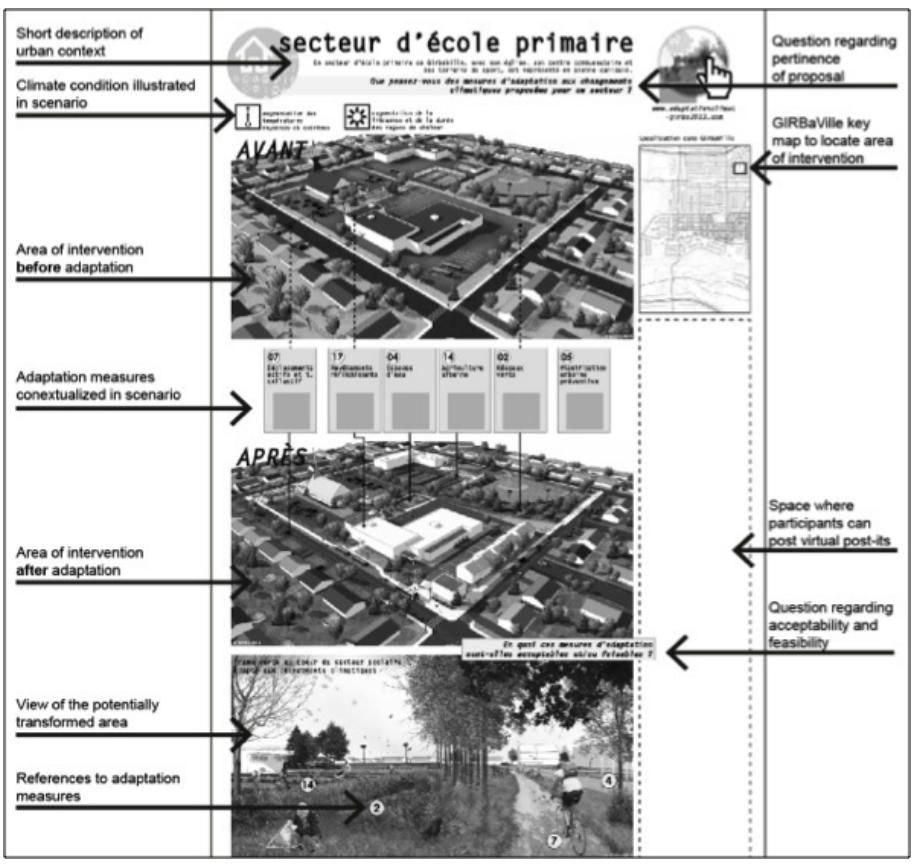

Figure 9: Example of scenario submitted to validation during July 2013 workshop, with GirbaVille key map (GIRBa, 2013)

20. The adaptation measure fact sheets were based on Catherine Dubois' doctoral research (Dubois, Cloutier et al, 2013) and the evolving design work. pencil questionnaire. Then, the team offered a brief presentation of basic principles and recommended actions regarding climate change and urban adaptations. This was followed by a presentation of the virtual city to be referred to during the day, and the vulnerability of its sectors in terms of urban form, housing types, density, and population. Potential social and physical vulnerability data underlying the scenarios was presented, coming, respectively, from the results of large Internet survey to Québec metro residents conducted in 2011 (Després, 2012) and from consultations conducted by the research team during Year 2. Each group of experts was then asked to discuss and comment the relevance and feasibility of the adaptations scenarios assigned to their team by using paper Post-it notes apposed to the printout scenarios. Each group was assigned three scenarios, one at each scale of intervention: neighbourhood, street and dwelling (fig. 11) ${ }^{22}$. Designated secretaries transcribed comments onto virtual Post-it notes on the virtual crowdsourcing platform. The evaluation by citizens is yet to be performed in August 2013. The results of these discussions are summarized in the next section.

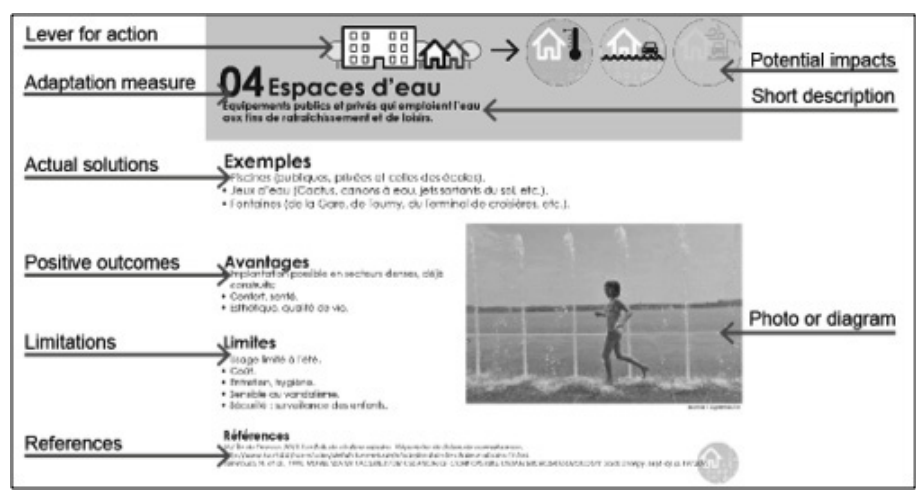

Figure 10: Example of adaptation measure fact sheet (GIRBa, 2013).

\subsection{What Have We Learned about the Feasibility and Acceptability of the Proposed Adaptations?}

The iterative and collaborative design and evaluation process put together by researchers, designers, and various stakeholders centred on the use of a crowdsourcing platform. The results underline at least two major positive outcomes: first, the co-construction of "local" knowledge based on scientific, technical and practice-based considerations shared by stakeholders, researchers and students alike; second, the realistic adjustment of general adaptation strategies to local contexts with the evaluation of their relevance.

21. Crowdbrite pages cannot contain hyperlinks to other sites, however. 


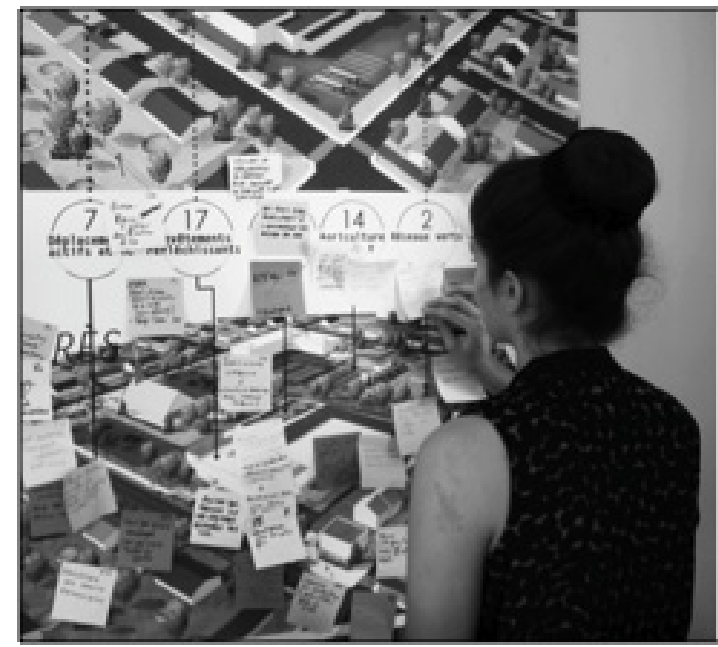

Figure 11: Validation workshop of adaptation scenarios involving 22 experts, July 2013 (GIRBa, 2013)

Regarding the knowledge base developed, a total of 738 comments on the proposed adaptation measures were made by eighteen citizens and forty experts ${ }^{23}$ involved either in the pre-test (Spring 2013) or the final evaluation (Summer 2013). Collected via the crowdsourcing platform, half of the comments were made during the July validation workshop ${ }^{24}$. Sémato@ was used as a qualitative analysis tool that helped identify networks of shared concepts based on semantic rules, thus leading to the identification of indicators as the basis of our analysis ${ }^{25}$ whose results are only preliminary. A further phase will compare participants' representations of the proposed adaptations according to their status as expert or non-expert, as well as socio-economic profile (age, gender, area and type of residence). Overall, about half of the comments by the experts during the final consultation expressed ambivalence about the proposed adaptations. This proportion is pretty much reflected at the neighbourhood and street scales of intervention, while there was even more disagreement at the residential scale (fig. 12a). The number of comments related to the feasibility and social acceptability of the adaptations, however, decreased as they applied to features closer to the home (fig. 12b).

At the neighbourhood scale (178 comments), the most mentioned adaptations concerned new or adapted public spaces, such as water parks, market places or parks. These were viewed positively as places for socializing that can especially benefit socio-economically vulnerable people. Urban agriculture in the form of collective gardens was similarly viewed as a good strategy to encourage sociability and increase food security, but also as a durable way to reduce the impact of urban heat

22. The scenarios were printed on large-size pages, accompanied by printed adaptation measure fact sheets. islands. Water parks, however, were considered less acceptable if located in places where security or surveillance is difficult to ensure. Replacing parking lots with new public spaces (such as a market place or a park) was considered acceptable but not, some say, if that meant less parking for commercial uses. Proposing curb-side school bus parking in favour of greening a larger portion of the school lot was considered unacceptable by some as it may create security problems. Enlarging sidewalks and creating pedestrian alleyways cutting through large urban blocks was viewed as acceptable and mostly feasible. However, greening existing paths was identified as even more feasible and less costly than investing

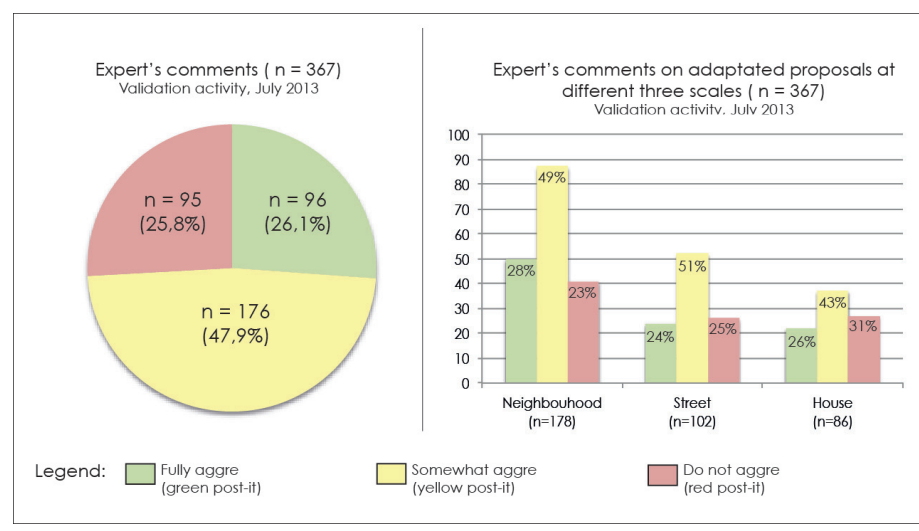

Figure 12: Proportion of comments formulated by experts during the evaluation (GIRBa, 2013)

23. None of the experts had participated to the pre-test.

24. While we cannot make direct comparisons between the two sets of results, we looked into the latter validation activity to get a broad sense of their opinion on the feasibility and acceptability of the proposed adaptation measures.

25. It was devised by the Centre d'analyse de texte par ordinateur (ATO) at Université du Québec à Montréal (www.ling.uqam.ca/ato/). 
in new infrastructures. Overall, even if experts are in agreement with encouraging walking and biking in an effort to reduce car dependency, such a measure was said to be unrealistic without appropriate incentives and public investment. Finally, in spite of a general agreement for a policy that would restrict or prohibit reconstruction in flood-prone areas (after a devastating flooding event, for instance), its political and legal feasibility was considered doubtful at best.

At the street scale (102 comments), the proposed adaptation to climate change that was considered the most acceptable and feasible is "greening". Apart from having a cooling effect, it is thought to improve the aesthetic quality of the streetscape as well as security for pedestrians. A small amount of comments considered the greening of commercial streets less feasible compared to residential streets, mainly for reasons of desirable visibility for shops and stores. Burying electrical lines to secure city power distribution in case of an extreme climatic event was viewed with scepticism because of cost, but also because of potentially unforeseen problems (like flooding, for instance). Landscape ditches to retain and filter runoff water (or bioswales) garnered the most comments at this scale of intervention. In principle, they are assessed as effective means to capture and prevent pollutant runoff while adding to green space to streets. However, they were said to be difficult and almost impossible to implement because of construction and maintenance costs, but also because of likely resistance from residents. Losing parking spaces for bioswales was also seen as unrealistic by some, especially along commercial streets where resistance is also to be expected, as political willingness to tackle this issue is doubtful.

At the house scale (86 comments), the adaptations that were considered most acceptable are also related to "greening", such as an apartment building parking lot partly transformed into a collective garden with shared amenities (like gazebos or play areas). Green roofs are also viewed as having a cooling effect in the city. As it was the case at the street scale, burying electrical lines was considered neither a priority nor financially realistic. However, greening residential mews ${ }^{26}$ and replacing the asphalt by a more porous material is considered unlikely because of cost (for construction and maintenance), potential rent hikes and resident resistance. In fact, many of the proposed adaptations on or nearby an apartment building were expected to cause rent hikes as an indirect result of the investment, even in the case of an agreement among tenants.

In sum, the consultation process has led to an important consensus regarding the feasibility and social acceptability of the proposed adaptation measures. It helped identify potential resistance to adaptation measures. Anticipating such resistance is crucial to ensure that the efforts of urban designers and local administrations to adapt the urban environment are effective (Sanyal, 2005). This process taught us that effective strategies towards enhancing urban resilience to climate change are "win-win" adaptation measures. For example, propositions including the greening of pedestrian pathways contribute to permeability and to mitigating the heat island effect, but also have the additional potential of strengthening the social fabric and encouraging active modes of transportation. In other words, our results so far point to the value of "multiple-advantage" measures that are simultaneously feasible, acceptable and cost-efficient. That being said, the collaborative process also pointed to challenges that need to be addressed in order to choose the most effective strategies for different local contexts.

\section{Cost and regulatory codes as main challenges}

According to experts, the biggest challenges posed by adaptation to climate change remain its cost and limitative regulatory codes. Although cost is most often associated to the amount of public investment involved in implementing the proposed adaptation measures, it was also referred to in terms of the long-term maintenance of infrastructure (like bioswales for instance), especially in the context of Québec snowy winters. In fact, the resilience of adaptations during the winter was considered very important. It also prompted some participants to point out the challenge to raise awareness on the potentially devastating impacts of urban heat island in a city where it is cold at least half of the year! Finally, if most adaptations were considered acceptable in principle, experts viewed codes and city regulations - such as zoning regulations or building codes - as strong barriers to implement the proposed scenarios.

\section{Greening as a readily feasible strategy}

Measures related to greening met strong endorsement because they appear relatively straightforward, less costly, less technically difficult to realise, and socially desirable. They are also viewed as an effective action to simultaneously improve the quality of citizens' life while also reducing the urban heat island effect. However, reducing parking space even for greening strategies is considered less acceptable and feasible by experts who mentioned resistance from businesses and municipal governments.

\section{Improving willingness and awareness}

Other adaptions were viewed as societal challenges by some participants namely adaptations aiming at encouraging active modes of transportation, implementing urban agriculture or conserving large green spaces as " cooling " areas throughout the city. According to some experts, convincing citizens of the acceptability - let alone the feasibility - of such costly actions in effectively reducing the negative impacts of climate change could prove difficult. Nevertheless, participants agreed on the importance of raising awareness not only within the public, but also within the private sector involved in urban development. The latter's involvement in some of the proposed adaptations requiring considerable public investment, like street renovation, is viewed as key to ensure their

26. The mews of Québec City's Limoilou neighborhood, our model for one scenario, are not in the public domain, hence the comments regarding ownership. 
success. This being said, participants also indicated that the need for further awareness and an overall " shift in mentalities " also applied to governing instances. Finally, the consulted experts all agreed for the need for a shared, multi-sectoral vision in preventive planning as one of the most important strategy towards adaptation to climate change.

The social acceptability and the feasibility of the proposed adaptations will be further evaluated during a public on-line consultation to be conducted in Fall 201327. Since participation cannot foster engagement without effective information, we are also working on Web 2.0 supported tools to help launch and sustain the consultation. Beyond the use of the crowdsourcing platform, the consultation strategy also comprises a custom-designed Web site with "how-to-participate" podcasts (www. adaptationclimat-girba2013.com), social media posts (via GIRBa's Facebook and Twitter accounts), direct email contacts, and Web networking (through hyperlinks).

\section{Conclusion}

Engaging experts and non-experts in actively thinking about the complex issue of city adaptation to climate change is a challenge that requires flexible participatory strategies allowing for the construction of placebased knowledge. This type of intersectoral and transdisciplinary participatory approach also bears the benefit of mobilizing local stakeholders and raising awareness about climate change, including city officials. In turn, it provides researchers, as well as students during their professional training, with multiple opportunities to acquire knowledge on climate change. The mobilization of participants in this process proved easy enough since the subject of the consultation was both pragmatic and local. Many knowledgeable actors on climate change were put into co-presence, leading to rising awareness of the issues and a form of empowerment ${ }^{28}$. These stakeholders were also quite willing to consider the adaptation strategies based on scientific evidence and expertise, as well as potential solutions, within the larger framework of urban sustainability.

Through a collaborative process such as this one, designers can inform researchers about issues and possibilities that would not have been otherwise identified or seen for their potential towards a pragmatic solution. It involves relying on subjective assessments of the best adaptation solution, which can challenge the scope of actions to be taken. What is a matter of public maintenance and what is the domain of private responsibility? What is readily or realistically feasible by local administrations, and what requires long-haul policy changes? Thus collaborative urban design is in itself a powerful strategy to effectively and realistically assemble and "translate" the results of empirical research and technical expertise so that they are validated in context and, more

27. The results and outcomes of this final consultation will be addressed by $\mathrm{MN}$ Chouinard in her ongoing Masters' thesis to be published in 2014. importantly, "understood" by everyone. In that sense, the outcomes of this project are already quite locally embedded, be they process-oriented or in forms more ready for appropriation (such as the illustrated adaption measures). This may pave the way to actual appropriation by policy and agents of change, and the gradual transformation of practices and society.

Visually-supported consultation strategies are quite efficient to reveal what people know and understand about the potential impact climate change bears on their comfort, health and safety, as well as the potential for the city's sustainable transformation. Developing a visual strategy during this participatory process also led to interesting lessons and outcomes, not the least being that representation, contextualization and information helps produce knowledge about the "territoriality" of climate change. Also, the diversity of representation modes aiming to inform, encourage mobilization and facilitate evaluation augments their flexibility of use in a crowdsourcing platform where they can support comments and activate debates. Our strategy oriented on the realistic and convivial quality of images has led to a set of representations that easily "transferable" in other contexts of intervention or consultation. They represent another key result for immediate appropriation by municipalities and other interested stakeholders as both an information or sensitization tool.

On-line consultation combined with face-to-face interaction have the potential of effectively bringing together different types of rationality and knowledge while creating a space to question, test and validate the feasibility and acceptability of adaptation measures regarding local factors and common practices. While crowdsourcing may represent a powerful tool to inform the population about climate change and its impacts on daily life, the experience proved relatively easy and convivial but demanded a fair amount of familiarization on the part of participants ${ }^{29}$. The usefulness of a participatory process to include in-person activities with intersectoral groups of stakeholders appears paramount. Working closely with various stakeholders while also combining Web tools for consultation such as crowdsourcing has considerably enriched the design proposals being adjusted along the way. The evaluation comments generated also allowed for the induction of pragmatic recommendations and actions in different forms - illustrated scenarios and fact sheets -- that can be used as decision aids by elected officials and civil servants to better prepare their municipalities for climate change.

28. A quick survey answered by 15 out of 22 of the experts who participated in July workshop indicates that the majority expressed their full agreement regarding the overall usefulness of the discussions' content for their own practice.

29. Our participants being hindered by the « how-to » of the new tool is not surprising, nor linked to our choice of platform. It is generally agreed that participatory Web tools tend to limit the deliberative context necessary for consensus building (Baek et al., 2011). 


\section{References}

Adger, W.N. "Vulnerability." Global Environmental Change-Human and Policy Dimensions.16.3 (2006): 268-281. Print.

Adger, W.N., and K. Vincent. "Uncertainty in Adaptative Capacity." C. R. Geoscience.337 (2005): 399-410. Print.

Al-Kodmany, K. "Public Participation: Technology and Democracy." Journal of Architectural Education 53.4 (2000): 220-28. Print.

Baek, Y.M., M. Wojcieszak, and M.X.D. Carpini. "Online Versus Face-toFace Deliberation: Who? Why? What? With What Effects?" New Media and Society 14.3 (2011): 363-83. Print.

Birkmann, J. (Ed.). Measuring Vulnerability to Natural HazardsTowards Disaster-Resilient Societies (2006). Tokyo : UNU Press. Print.

Boholm, A., and R. Löfstedt. "Facility Siting: Risks, Power and Identity in Land Use Planning." Risks, Society and Policies Series. London: Earthscan, 2004. Print.

Brabham, D.C. "Crowdsourcing the Public Participation Process for Planning Projects." Planning Theory 8.3 (2009): 242-62. Print.

--. "Motivation for Participation in a Crowdsourcing Application to Improve Public Engagement in Transit Planning." Journal of Applied Communication Research 40.3 (2012): 307-28. Print.

Brown, V.A., J.A. Harris, and J.Y. Russell. Tackling Wicked Problems through the Transdisciplinarity Imagination. London: Earthscan, 2010. Print.

Bugs, G., C. Granell, O. Fonts, J. Huerta, M. Painho. "An Assessment of Public Participation GIS and Web 2.0 Technologies in Urban Planning Practice in Canela, Brazil." Cities.27 (2010): 172-81. Print.

Bulkeley, H. "Cities and the Governing of Climate Change." Annual Review on Environmental Ressources 35 (2010): 229-53. Print.

CEFRIO. "Les Médias Sociaux." NETendances 2012 - Évolution de l'utilisation d'Internet au Québec. 2012. Web, December 2012.

Cloutier, G., F. Joerin (2012) "Tackling Climate Change Adaptation at the Local Level through Community Participation." Urban Areas and Global Climate Change, Ed. W.G. Holt, Vol. 12, Research in Urban Sociology: Emerald Group Publishing Limited (2012): 51-73. Print.

DeCindio, F., and C. Peraboni. "Building Digital Participation Hives: Toward a Local Public Sphere." From Social Butterfly to Engaged Citizen ; Urban Informatics, Social Media, Ubiquitous Computing, and Mobile Technology to Support Citizen Engagement Eds. Foth, M., et al. Cambridge, Massachusetts: MIT Press, 2012. 93-113. Print.

DesJarlais, C., M. Allard, D. Bélanger, A. Blondlot, A. Bouffard, A. Bourque, D. Chaumont, P. Gosselin, D. Houle, C. Larrivée, N. Lease,
A.T. Pham, R. Roy, JP. Savard, R. Turcotte et C. Villeneuve. Savoir s'adapter aux changements climatiques. Montréal: Ouranos, 2010. Print.

Després, C. "Les préférences résidentielles des habitants de la CMQ qui envisagent déménager d'ici 2012. Présentation de résultats de l'enquête Demain Québec : Une enquête pour informer l'aménagement de nos villes." Les entretiens sur l'habitat de la Société d'Habitation du Québec (SHQ), 2012. Conference paper.

Després, C., G. Vachon (2013) Québec 2020 : A Transdisciplinary and ICT-Supported Approach to Build Consensus around a Sustainable Vision for the Metropolitan Area. European Network for Housing Research (ENHR). June 19th 2013. Conference paper.

Després, C., G. Vachon and A. Fortin "Implementing Transdisciplinarity : Architecture and Urban Planning at Work." Transdisciplinary Knowledge in Architecture and Urbanism : Towards Hybrid Modes of Inquiry. Eds. Doucet, I. and N. Janssens. New York: Springer, 2011. Print.

Després, C., G. Vachon, A. Fortin, P. Gauthier, P. Larochelle «Inertie des habitus et évolution des types architecturaux dans l'habitat de banlieue à Québec.» Housing Reconsidered : Echoes of Applied Research. Eds. Barbey, G. and R.J. Lawrence. Gollion, Suisse: Editions Infolio, forthcoming. Print.

Dodge, M., and R. Kitchin. "Crowdsourced Cartography: Mapping Experience and Knowledge." Environment and Planning A 45.1 (2013): 19-36. Print.

Dubois, C., G. Cloutier, L. Adolphe, A. Potvin "Vers une architecture et un design urbain adpaptés: intégrer les contraintes du dérèglement climatique au processus de conception." Cloutier, G., F. Joerin, C. Dubois, M. Labarthe, C. Legay, G. Vachon, C. Després, A. Potvin, M. Rodriguez, M.H. Vandersmissen Changements climatiques et transformation urbaine: un projet de recherche-action pour renforcer la résilience de la $C M Q$, Final Research Report, Chaire en aide à la decision territoriale, Université Laval, Québec. 2013. Print.

Foth, M. "Network Action Research." Action Research 4.2 (2006): 20526. Print.

Gordon, E., and E. Manosevitch. "Augmented Deliberation: Merging Physical and Virtual Interaction to Engage Communities in Urban Planning." New Media and Society 13.1 (2010): 75-95. Print.

Gordon, E., S. Schirra, and J. Hollander. "Immersive Planning: A Conceptual Model for Designing Public Participation with New Technologies." Environment and Planning B: Planning and Design 38 (2011): 505-19. Print.

Hallegatte, S. "Strategies to Adapt to an Uncertain Climate Change." Global Environmental Change 19 (2009): 240-45. Print. 
Hayek, U.W. "Which Is the Appropriate 3D Visualization Type for Participatory Landscape Planning Workshop ? A Portfolio of Their Effectiveness." Environment and Planning B: Planning and Design.38 (2011): 921-39. Print.

IPCC. Climate Change 2007: Synthesis Report. Contribution of Working Groups I, II and III to the Fourth Assessment Report of the Intergovernmental Panel on Climate Change. Geneva: IPCC, 2007. Print.

ISQ, Institut de la Statistique du Québec. Science, technologie et innovation en bref. L'Accès des ménages à Internet. Gouvernement du Québec, 2013. Print.

ISQ, Institut de la Statistique du Québec. Perspectives Démographiques du Québec et des regions, 2006-2056: Gouvernement du Québec, 2009. Print.

Klein, R.J.T, E.L. Shipper, and S. Dessai. "Integrating Mitigation and Adaptation into Climate and Development Policy: Three Research Questions." Environmental Science and Policy 8 (2005): 579-88. Print.

Mandarano, L., M. Meenar, and C. Steins. "Building Social Capital in the Digital Age of Civic Engagement." Journal of Planning Literature 25.2 (2010): 123-35. Print.

O'Reilly, T. "What Is Web 2.0 : Design Patterns and Business Models for the Next Generation of Software." 2005. Web. March 12th 2013.

Perthuis, Christian de. Et Pour Quelques Degrés De Plus... Changement Climatique : Incertitudes Et Choix Économiques. 2nd ed: Pearson, 2010. Print.

Proulx, S. "Can the Use of Digital Media Favour Citizen Involvement?" Global Media and Communication 5.3 (2009): 293-307. Print.

Rittel, H. and M. Webber, "Dilemmas in a General Theory of Planning", Policy Sciences 4 (1973): 155-169. [Reprinted in Developments in Design Methodology. Edited by Cross, N., Chichester: J Wiley \& Sons (1984): 135-144]. Print.

Sanyal, B. "Planning as Anticipation of Resistance", Planning Theory, 4.3 (2005): 225-245. Print.

Senbel, M., and S.P. Church. "Design Empowerment: The Limits of Accessible Visualization Media in Neighbourhood Densification." Journal of Planning Education and Research 31.4 (2011): 423-37. Print.

Slotterback, C.S. "Planners' Perspectives on Using Technology in Participatory Processes." Environment and Planning B: Planning and Design 38 (2011): 468-85. Print.

Söderström, O. "Figures De L'intermédiation." Des images pour agir: Le visuel en urbanisme. Lausanne: Payot, 2000. Print.

Steininger, S., M.E. Poorazizi, C. Bliss-Taylor, E. Mohammadi, A.J.S. Hunter. "Planyourplace: Merging Social Networks and Participatory GIS for Participatory Planning." Knowing to manage the territory, protect the environment, evaluate he cultural heritage. 2012. Print.

Stern, E., G. Ori, and S. Tal. "Web-Based and Traditional Public Participation in Comprehensive Planning: A Comparative Study." Environment and Planning B: Planning and Design 36.6 (2009): 106785. Print.

Tompkins, E.L., W.N. Adger, E. Boyd, S. Nicholson-Cole, K. Weatherhead, N. Arnell. "Observed Adaptation to Climate Change: UK Evidence of Transition to a Well-Adapting Society." Global Environmental Change 20 (2010): 627-35. Print.

Vachon, G., G. Cloutier, M.N. Chouinard, Després, C. Dubois "Adapting the Resident Landscape to Climate Change: An ActionResearch Agenda to Imagine Design Solutions, Measure Their Social Acceptability and Inform Planning Decisions." European Network for Housing Research (ENHR). June 20 ${ }^{\text {th }}$ 2013. Conference paper.

Williams, K., J. Joynt, and D. Hopkins. "Adapting to Climate Change in the Compact City: The Suburban Challenge." Built Environment 36.1 (2010): 105-15. Print. 